\title{
COMMON HEALTH PROBLEMS IN GERIATRIC PATIENTS: A CROSS- SECTIONAL HOSPITAL BASED STUDY
}

\section{Anup Singh}

Associate Professor \& Head, Department of Geriatric Medicine, Institute of Medical Sciences, BHU, Varanasi, India-221005

Article Info: Received 18 January 2019; Accepted 10 February. 2019

Cite this article as: Singh, A. (2019). COMMON HEALTH PROBLEMS IN GERIATRIC PATIENTS: A CROSSSECTIONAL HOSPITAL BASED STUDY. Journal of Biomedical and Pharmaceutical Research, 8(1).

DOI: https://doi.org/10.32553/jbpr.v8i1.574

Address for Correspondence: Anup Singh, Associate Professor \& Head, Department of Geriatric Medicine, Institute of Medical Sciences, BHU, Varanasi, Uttar Pradesh, India-221005

Conflict of interest statement: No conflict of interest

\section{ABSTRACT:}

Background: The health problems of elderly are often nonspecific and the pattern of disease keeps changing. Therefore, it is essential to know the burden of disease especially in developing countries so that policy could be made to overcome the morbidity associated with it. The present study was done to identify the geriatric health problems in geriatric patients coming to Geriatric clinic in a tertiary care centre.

Methods: A hospital based cross-sectional study was carried in Geriatric clinic with patients aged over 60 years in 100 patients. Basic demographic data and clinical history was taken by physician. Categorical variables were summarized by percentages. Associations were explored with odds ratio (OR) and 95\% confidence intervals (Cls).

Results: Out of 100 patients 61 were males and 39 were females. Visual impairment was the most common handicap with prevalence of $89 \%$, with males more affected than females. Weight loss was there in $47 \%$ of patients. Forty two percent(42\%) has depression and $41 \%$ has arthritis. Apart from these uncorrected hearing impairment was present in $46 \%$ of patients. Urinary complaints were more common in males.

Conclusion: It was found that elderly population has all kind of ailments so a multidispliniary approach should be there in every Geriatric Clinic so that each co-morbid condition can be taken care off.

\section{INTRODUCTION}

It has been estimated that by 2050, elder people will outnumber the number of children under 14 years of age. [1] Geriatric population are prone to multiple ailments because of normal physiological decline. Also the health in young life also effects the health at later stage. A person with early onset diabetes or hypertension will be at high risk of various complication of these diseases at older age. Further, the health services are poor for geriatric population in developing countries. So, it becomes a challenge to identify the diseases which are common in elderly so that national policies may be made to overcome these challenges. Therefore, multiple crosssectional surveys are important to identify the challenges of geriatric healthcare in future. 
Anup Singh, Journal of Biomedical and Pharmaceutical Research

Various studies have been done in India with relation to social and health related issues of geriatric population.[2-5]

The present study was done to identify the geriatric health problems in Geriatric patients coming to Geriatric clinic in a tertiary care centre.

\section{Material and Methods:}

A cross sectional study was conducted in Geriatric outpatient clinic of Department of Geriatric Medicine, Institute of Medical Sciences, BHU which is a tertiary care centre in Eastern Uttar Pradesh.

100 prospective patients of more than 60 years of age coming to Geriatric outdoor clinic were taken in the study. Where the elder patient could not communicate, care giver help was taken. Presence of morbidity was detected by self-reporting, supplemented by clinical history, detailed clinical examination and relevant previous investigations.

Data entry and statistical analysis

Data were entered in a Microsoft Excel file and statistical analysis was done using SSPS software. Categorical variables were summarized by proportions and percentages. Association between categorical variables was explored by Chi square and odds ratio (OR) with 95\% confidence intervals (Cls) where applicable. Continuous variables were summarized by mean and standard deviation (SD), and association tested by parametric tests.

\section{Results:}

Out of 100 patients, 61 were males and 39 were females. The overall mean age in elderly females was 63.24 years, and in males it was 65.15 years. The combined average of all elderly was 64.19 years. The maximum age among females was 83 years, while for males it was 91 years. Majority of the elderly, $62 \%$ (228/407) were in the age group of $60-69$ years. Hindus constituted 90\%, Muslims 5\% , Sikh $3 \%$ and Christian were $2 \%$ of the population.

Among the total elderly, 38\% were illiterate, $43 \%$ had received primary education, $19 \%$ had received secondary education while none had received education up to the graduate level. The proportion of illiterates was much more among females $53.84 \%(21 / 39)$ as compared with males $27.86 \%$ (17/61).

Table 1 shows the various ailments/diseases by which patients came to outdoor clinic. Apart from the morbidities mentioned in table 1 patients were having ailments like Diabetes Miletus, Ischemic heart disease, Asthma, COPD, Parkinsonism, Malignancy and Paralysis.

Diabetes mellitus was present in 5 male patient and 3 female patient. There was 3 male and 1 female patient of ischemic heart disease and 2 male patient each of prostatic malignancy, cerebrovascular accident, and Parkinsonism.

Table 1: Frequency of Various morbidities in elderly patients

\begin{tabular}{|l|l|l|l|l|}
\hline & Present & Absent & P-Value & Odds ratio (95\% CI) \\
\hline Weight loss & & & & \\
\hline Males & $25(40.98 \%)$ & $36(50.01 \%)$ & & \\
\hline Females & $22(56.41 \%)$ & $17(43.58 \%)$ & & \\
\hline Total & 47 & 53 & 0.132 & $0.537(0.238-1.210)$ \\
\hline Urinary complaints & & & & \\
\hline Males & $12(19.6 \%)$ & $49(80.32 \%)$ & & \\
\hline Females & $5(12.82 \%)$ & $34(87.17 \%)$ & & \\
\hline
\end{tabular}


Anup Singh, Journal of Biomedical and Pharmaceutical Research

\begin{tabular}{|l|l|l|l|l|}
\hline Total & 17 & 83 & 0.374 & $1.665(0.537-5.162)$ \\
\hline Visual impairment & & & & \\
\hline Males & $58(95.08 \%)$ & $3(4.91 \%)$ & & \\
\hline Females & $31(79.48 \%)$ & $8(20,51 \%)$ & & \\
\hline Total & 89 & 11 & 0.015 & $4.989(1.234-20.166)$ \\
\hline Depression & & & & \\
\hline Males & $22(36.06 \%)$ & $39(63.93 \%)$ & & \\
\hline Females & $20((51.28 \%)$ & $19(48.71 \%)$ & & \\
\hline Total & 42 & 58 & 0.133 & $0.536(0.237-1.213)$ \\
\hline Arthritis & & & & \\
\hline Males & $21(34.42 \%)$ & $40(65.57 \%)$ & & \\
\hline Females & $20(51.28 \%)$ & $19(48.71 \%)$ & & \\
\hline Total & 41 & 59 & 0.095 & $0.499(0.220-1.133)$ \\
\hline Dental Problems & & & & \\
\hline Males & $19(31.14)$ & $42(68.85 \%)$ & & \\
\hline Females & $9(23.07 \%)$ & $30(76.92 \%)$ & & \\
\hline Total & 28 & 72 & 0.381 & $1.508(0.600-3.788)$ \\
\hline Hypertension & & & & \\
\hline Males & $20(32.78 \%)$ & $41(67.21 \%)$ & & \\
\hline Females & $11(28.20 \%)$ & $28(71.79 \%)$ & & \\
\hline Total & 31 & 69 & 0.629 & $1.242(0.516-2.990)$ \\
\hline
\end{tabular}

\section{Discussion:}

Geriatric health care is faced with various challenges as various diseases present with non- specific signs and symptoms. Apart from diagnosis, the treatment aspect is equally challenging because of co-existing comorbidities and various drug interactions. World Health Organization (WHO) in collaboration with the Government of India carried out a cross-sectional, community-based study of the elderly population 60 years and above at 10 different sites in different states and union territories of India to see the burden of increasing geriatric health and social problems in India.[6] In this hospital based study, we found a very high percentage of patients with visual impairment (89\%), which is higher than $45.4 \%$ as found in the WHO study.[7] In India, the scarcity of ophthalmologist poses a great difficulty to tackle this and people use other untrained persons for their visual complaints. However, various eye camps programmed by government and various NGO's for cataract which is commonest blinding condition in India.[8] More such camps should be done in rural setting seeing the high prevalence of visual disturbances with increasing age.

Patients with urinary problems (17\%) was similar to the findings of the WHO multicentric study.[6] The higher percentage of urinary complains in males is because of benign prostatic hypertrophy in elderly males.

Sedentary lifestyle with associated obesity will increase the incidence of many noncommunicable diseases in the elderly, such as coronary heart disease, diabetes and osteoarthritis. In our study, $41 \%$ patient had osteoarthritis, $31 \%$ has hypertension. Studies have shown that prevalence of hypertension is between $20-30 \%$ in rural India. $[9,10]$ Noncommunicable and degenerative disease are very common in elderly due to physiological decline in function of various organ system.[11] 
Geriatric mental health is also a concern for geriatric health care. $42 \%$ of patients complained of depression in the past 6 months. $28 \%$ patient had dental problems which is also a common accompaniment of ageing. The scare number dentist in rural area warrants the need of appropriate planning for dental care for the elderly by organising dental camps in remoter area.

Limitation of the study includes less sample size and being a hospital based study we cannot extrapolate the findings with the general population. In spite of the above limitations, the study established the fact that variety of morbidity co-exist in geriatric population. Heath care for geriatric population is very poor in addition to social and psychological issues. There is need of development of health policies for elderly people to combat the increasing population of geriatric age group and more geriatric clinics should be established in Medical College and government hospitals for comprehensive healthcare of elderly.

\section{Footnotes}

Source of Support: Nil.

Acknowledgement: National Program for healthcare of Elderly, MoHFW.

\section{References}

1. WHO. World Health Day-toolkit for organizers. Available from: http://www. who.int/world.health.day/2012/toolkit/ba ckground/en/index.html

2. Bhatia SP, Swami HM, Thakur JS, Bhatia V. A study of health problems and loneliness among the elderly in Chandigarh.Indian J Community Med. 2007 32:255-8.

3. Pandve HT, Deshmukh P. Health survey among elderly population residing in an urban slum of Pune city. J Indian Acad Geriatr. 2010 6:5-8.

4. Lena A, Ashok K, Padma M, Kamath V, Kamath $A$. Health and social problems of the elderly: A cross sectional study in Udupi taluk, Karnatka. Indian J Community Med. 2009;34:131-4.

5. Prakash R, Choudhury SK, Singh US. A Study of morbidity pattern among geriatric populaton in an urban area of Udaipur Rajasthan.Indian J Community Med. 2004 29:35-40.

6. World Health Organization Collaborative Programme supported by the Government of India. Multicentric study to establish epidemiological data on health problems in elderly. Availablefrom:http://www.who india.org/LinkFiles/Health_Care_for_the_E Iderly_Multicentric_study_healthcareelder ly_exe.pdf .

7. Park K. Park's text book of preventive and social medicine. 21st ed. Jabalpur, India: M/S Banarsidas Bhanot; 2011. Blindness; pp. 370-4.

8. Park K. Visual Impairment and Blindness. In: Park K, editor. Park's textbook of preventive and social medicine. 22nd edition. Jabalpur, India: Banarsidas Bhanot; 2013. pp. 371-4.

9. Kishore J,Gupta N, Kohli C , et al Prevalence of hypertension and determination of its risk factors in Rural Delhi. Int J Hypertens 2016;2016:16.doi:10.1155/2016/7962595

10. Bansal SK ,Saxena V ,Kandpal SD, et al. The prevalence of hypertension and hypertension risk factors in a rural Indian community: A prospective door-to-door study. J Cardiovasc Dis Res 2012;3:117-23.

11. Boss GR, Seegmiller JE. Age-related physiological changes and their clinical significance. West J Med. 1981;135(6): 434-40. 